\title{
O PROBLEMA DA EDUCAÇÃO NA CONSTRUÇÃO DO ÚNICO EM MAX STIRNER
}

\author{
Renato Almeida de Oliveira ${ }^{1}$ \\ Sandro Soares Rodrigues ${ }^{2}$
}

\begin{abstract}
Resumo:
Este estudo buscará investigar as condições de formação do Único, proposto por Max Stirner, a partir da educação. O problema relacionado à questão do indivíduo e à individualidade se tornou o ponto central do trabalho de Stirner, representando este, o radicalismo em torno do tema. Percebemos a necessidade dessa pesquisa a partir da lacuna que o autor deixou em sua obra magna $O$ Único e sua propriedade (1844) em torno do indivíduo, naquilo que se refere as condições reais para sua efetivação. Encontramos na obra $O$ falso princípio da Educação (1842), os pressupostos necessários para a construção do Único. Apresentaremos a crítica stirneriana aos modelos tradicionais de educação de seu tempo, assim como as perspectivas para sua superação a partir de uma nova concepção de educação que visa a autodeterminação do indivíduo, ultrapassando, desse modo, a educação servil ao Estado a qual, segundo nosso autor, aliena o homem de sua unicidade.
\end{abstract}

Palavras-chave: Max Stirner. Indivíduo. Único. Educação.

\section{THE PROBLEM OF EDUCATION IN THE CONSTRUCTION OF THE INDIVIDUAL WITHIN MAX STIRNER}

\begin{abstract}
:
This study seeks to investigate the conditions of Ego's formation through education, proposed by Max Stirner. The problem related to the individual and the individuality has become the main point of Stirner's work, representing this, the radicalism around the subject. We realized the necessity of this research from the gap left by the author in its magnum opus, The Ego and Its Own (1844) around the individual, in what refers to the real conditions for its realization. We found within the work The False Principle of our Education (1842), the necessary presumptions for the Ego's construction. We will present Stirner's critique on the traditional educational models of his time, as well as the perspectives for its overcoming from a new conception of education that aims an individual self-determination, thereby transcending servile education to the State, which, according to the author, alienates the man of his uniqueness.
\end{abstract}

Keywords: Max Stirner. Individual. Ego. Education.

\section{Introdução}

1 Doutor em Filosofia pela Universidade Federal do Ceará (UFC). Professor Adjunto do Curso de Filosofia da Universidade Estadual Vale do Acaraú (UVA). E-mail: renatofilosofosds@yahoo.com.br

2 Mestre em Filosofia pela Universidade Federal do Ceará (UFC). Professor de Filosofia do Instituto Federal do Pará (IFPA). Vice-líder do Grupo de Pesquisa "Saberes, educação, interculturalidade e variações temáticas sobre a Amazônia" (SEIVA), vinculado ao (IFPA). E-mail: sandro.rodrigues@ifpa.edu.br. 
Visando uma compreensão mais abrangente do estudo aqui apresentado, faz-se necessária, em caráter preambular, uma sucinta exposição da concepção Stirneriana em relação ao indivíduo. A Questão sobre o indivíduo ${ }^{3}$, em Max Stirner, fora elaborada e desenvolvida na obra $O$ Único e a sua Propriedade, cujo título “[...] mostra que todo o seu sistema é fundado na singularidade do Eu." (LÉVY, 2012, p. 73). Apresentaremos, a seguir, o desenrolar desta questão a partir de uma leitura imanente da referida obra.

As questões relacionadas ao indivíduo e à individualidade tornaram-se centrais durante a modernidade ${ }^{4}$, representando Stirner o radicalismo em torno de tal discussão, pois, conforme Dias, “[...] desde logo temos de reconhecer que poucas vezes ao longo do pensamento filosófico sustentou-se uma defesa mais apaixonada, mais titânica e, pode-se dizer, mais feroz do ego, que a levada a cabo por este alemão chamado Kaspar.” (DIAS, 2002, p. 24)

Enunciando de forma objetiva, o indivíduo para Stirner goza de uma existência incondicionada, inteiramente livre, ocupando um lugar central, singular, única no mundo. Em outros termos, o indivíduo stirneriano encontra-se numa esfera na qual nada lhes é anterior ou posterior, onde nenhum poder se lhe impõe, nenhum condicionamento o restringe, sendo livre de quaisquer constrangimentos, imposições ou deveres.

A construção de um indivíduo, o qual preservará intocável sua individualidade, exige a desmistificação de todos e quaisquer ideais ou ideias com os quais os indivíduos foram alienados ao longo da história. Desse modo, "fica claro, então, que as ideias que Stirner pretende aniquilar não são meramente representações, mas ideais a cuja realização os homens devem servir, diante das quais o indivíduo deve curvar-se em detrimento de si mesmo." (SOUZA, 1993, p. 25).

Segundo Stirner, no processo de formação deste exemplar de individualidade, é mister a desconstrução de todas as "ilusões" criadas ao longo da História Universal, as quais retiraram do indivíduo aquilo que lhe é mais próprio e íntimo, ou seja, retiraram-lhe a sua singularidade, usurparam-lhe de seu Eu; alienaram-

3 Esclarecemos que a utilização do termo "Indivíduo", sob a perspectiva stirneriana, faz referência ao Único ou Eu-Proprietário, haja vista que Stirner não utiliza o termo "indivíduo". Contudo, seguiremos utilizando-o, de forma didática para uma maior compreensão da temática. Adotaremos o mesmo entendimento de Souza (1993) na utilização do referido termo. Concluímos não existir prejuízos à pesquisa nem ao desenvolvimento do trabalho.

4 Veja a esse respeito, entre outros: SOUZA, 1993; SCHAFF, 1967.

\begin{tabular}{|l|l|l|l|l|}
\hline Q Rovista Q Olalectus & Ano 5 & n. 12 & Janeiro - Julho 2018 & p. 223-240 \\
\hline
\end{tabular}




\section{O PROBLEMA DA EDUCACÃ̃O NA CONSTRUCÃ̃O DO ÚNICO...}

Renato Almeida de Oliveira / Sandro Soares Rodrigues

no com ideias fixas, diluindo o Eu, na categoria "homem", ou "humanidade". Ao ver de Souza (1993), ao desenvolver toda uma gênese acerca dos ideais, Stirner tenta encenar uma exposição ampliada de como chega a se construir e como pode evoluir a dominação do indivíduo pelo Espírito. Stirner conclama o indivíduo a revoltar-se, a rebelar-se contra a condição servil e hipócrita que lhe fora imposta pela cultura e pela educação por inúmeros meios.

Evidenciam-se, em termos práticos, questões fulcrais à construção do indivíduo singular, do Único: quais as ferramentas e quais os meios serão utilizados para a gestação deste exemplar de indivíduo? A proposta stirneriana de um indivíduo Único é viável?

\section{Superação dos modelos tradicionais de educação como pressuposto da construção da Unicidade}

Stirner, consciente da necessidade de um maior embasamento para suportar seu arquétipo de indivíduo, formulou, dois anos antes da publicação de sua obra magna, um artigo que se consolidaria como um preâmbulo de $O$ Único e sua Propriedade. Estamos nos referindo a O Falso Princípio da Educação, publicado na Gazeta Renana, em abril de 1842 .

Nosso filósofo buscava encontrar o "nome" que melhor exprimisse o tempo no qual estava inserido. Ele sabia que tal descoberta definiria os rumos da sociedade, por isso não se demorou a investigar quais eram as maiores influências ideológicas que formavam as consciências em seu tempo, afim de criticá-las e apresentar um modelo que servisse ao seu indivíduo Único.

Seu ponto de partida foi criticar a publicação de Theodor Heinsius ${ }^{5}$, em 1842, do ensaio "Concordância entre a escola e a vida, ou conciliação entre Humanismo e Realismo, encarada do ponto de vista nacional”. Neste ensaio, Heinsius tentava conciliar os dois grandes modelos pedagógicos dominantes na Alemanha no final do século XIX, a saber, o Humanismo e o Realismo ${ }^{6}$. Segundo Stirner, a busca

Théodore Heinsius (1770-1849): filósofo renomado. Professor e diretor do Couvent-Gris, em Berlim, publicou gramáticas, dicionários e uma história da literatura alemã.

6 O humanismo foi predominante do intervalo de tempo entre a Reforma Protestante e a Revolução Francesa. A educação é fundamentada nos estudos dos clássicos, dos textos bíblicos, das línguas antigas, além da valorização da cultura do gosto, da forma e da elegância de estilo. É notória a resistência do humanismo ao desenvolvimento científico e tecnológico. O realismo, inspirado pelo século das luzes, inspira-se nos ideais de liberdade, igualdade e fraternidade. Portanto, baseia a educação a partir dos direitos do homem, do conhecimento das ciências teóricas e experimentais,

\begin{tabular}{|l|l|l|l|l|}
\hline Rovista Dialectus & Ano 5 & n. 12 & Janeiro - Julho 2018 & p. 223-240 \\
\hline
\end{tabular}




\section{O PROBLEMA DA EDUCACÃO NA CONSTRUCÃO DO ÚNICO...}

Renato Almeida de Oliveira / Sandro Soares Rodrigues

pela peça mestra, fundamental à construção de um novo exemplar de indivíduo, assim como de um novo tipo de relações sociais estava sendo buscada da forma errada. Tanto o humanismo, quanto o realismo, assim como as ideologias políticas e partidárias, representavam apenas os cadáveres em decomposição do passado, sendo revirados pelas aves de rapina ou, em outros termos, os intelectuais da época. Portanto,

[...] para as duas escolas pedagógicas que Stirner critica, a humanista e a realista, uma preocupada com a formação clássica, a outra, em dotar os cidadãos de saberes cívicos e saberes aptos a "ganhar a vida", a educação não era outra coisa senão acumulação de conhecimentos, e, na verdade, conquanto aparentem posições contrárias, não deixam de ser equivalentes. (FERRER apud STIRNER, 2001, p. 19).

O posicionamento aversivo de Stirner em relação à tentativa conciliadora de Heinsius delimita sua intenção: derrubar as ideologias e os modelos pedagógicos existentes. Notoriamente, Stirner vislumbra a ferramenta necessária à construção do seu Único: a educação. Haja vista que,

Sem nossa intervenção, nosso tempo não dará origem ao termo adequado; devemos todos juntos trabalhar com esse fim. Todavia, se essa obra depende de nós, é bom que nos perguntemos o que fizeram e o que se propõem a fazer de nós; qual é, então, essa educação graças à qual tentam fazer de nós os criadores desse termo? Cultivam, em consciência, nossa predisposição à criação ou nos tratam apenas como criaturas unicamente suscetíveis de adestramento? Esse problema é tão importante quanto qualquer problema social: em verdade, é o mais importante pois, em fim de contas, os problemas sociais repousam sobre essa base. (STIRNER, 2001, p. 61-62).

Percebemos, na assertiva anterior, que Stirner, apesar de estar imbuído das discussões envolvendo teologia, economia e filosofia, no âmbito da esquerda hegeliana, aponta para uma questão essencial para a formação do indivíduo e, por conseguinte, da sociedade.

Ao trazer a educação e os seus pressupostos como eixos centrais para compreensão dos problemas sociais, Stirner esboça sua crítica aos sistemas dominantes; ao questionar os pressupostos e objetivos da educação vigente, ele simultaneamente questiona as bases das relações de poder. Portanto, anterior às discussões sobre a divisão social do trabalho, a desmitificação da realidade, a derrubada dos modelos de

visando à formação técnica e profissional. Vale frisar que o uso que Stirner faz do termo humanismo não se refere diretamente a esta corrente nascida na Reforma e que se desenvolveu até a Revolução. Ele utiliza o termo num sentido muito particular e que remete à velha expressão "fazer suas humanidades", ou seja, o percurso do ensino clássico que consistia em humanidades, retórica e filosofia. (Cf. BARRUÉ, 200, p. 28-41).

\begin{tabular}{|c|c|c|}
\hline Qenista Dialectus & Ano 5 & n. 12 \\
\hline
\end{tabular}




\section{O PROBLEMA DA EDUCACÃ̃O NA CONSTRUCÃ̃O DO ÚNICO...} Renato Almeida de Oliveira / Sandro Soares Rodrigues

dominação, está a discussão em torno do tipo de indivíduo que se deseja formar. O olhar de Stirner consegue ultrapassar as querelas em torno das questões teóricas, abstratas, conceituais, e mira uma questão vital, imprescindível.

Tratar dos objetivos pedagógicos e questionar os modelos existentes é, ao mesmo tempo, abrir caminho para o novo. Para Stirner, não basta apenas responder à questão “o que ensinar?", mas também às seguintes: “como ensinar?” e "qual o objetivo de ensinar?". Portanto, a questão mais relevante não é de caráter conteudístico, e sim da forma e da finalidade da educação. De outra maneira: em primeiro lugar devem estar as questões antropológicas, ou seja, ligadas a que tipo de pessoa um determinado modelo de educação quer formar, ou ainda, para qual sociedade se está sendo preparado o indivíduo. Somente a partir disso virá o segundo passo, que consiste no embasamento epistemológico, ou seja, o que ensinar e, por fim, a base metodológica, as metodologias utilizadas para os fins estabelecidos.

Para Stirner, tanto o humanismo quanto o realismo, guardadas as respectivas proporções, apontam para o caminho oposto de criação da unicidade do indivíduo, da igualdade consigo. Portanto,

[...] ser igual aos outros, ser livre dos outros, não nos conduz a essa igualdade consigo próprio, a essa liberdade em si mesma da qual depende a reconciliação do que há em nós de temporal e eterno, de nosso corpo e de nosso espírito. Devemos chegar à unidade e à onipotência de nosso Eu. (BARRUÉ apud STIRNER, 2001, p. 28).

Ao ver de Stirner, o humanismo e o realismo fracassaram, pois, o primeiro deve renunciar à pretensão de instaurar uma "cultura superior", enquanto o segundo está limitado à formação do homem prático. Desse modo, o humanismo, ao formar homens eruditos, e o realismo, cidadãos utilizáveis, apenas constroem o servilismo e a debilidade.

\section{Educação, cultura e poder}

Ao abordar o problema da educação, Stirner adentra em outra questão basilar na constituição do indivíduo: a cultura ${ }^{7}$. Indiscutivelmente, educação e cultura estão entrelaçadas, pois, ao passo que a primeira serve de meio para transmissão da

\footnotetext{
7 Tomaremos o conceito antropológico de cultura como aquilo que distingue a ação humana da ação dos demais animais. A cultura como construto exclusivamente racional, histórico e social. (Cf. ARANHA, 2006). Também consultar em VAZ, 1997, p. 3-115.
}

\begin{tabular}{|l|l|l|l|l|}
\hline Q Povista 2 Dialectus & Ano 5 & n. 12 & Janeiro - Julho 2018 & p. 223-240 \\
\hline
\end{tabular}




\section{O PROBLEMA DA EDUCACÃ̃O NA CONSTRUCÃ̃O DO ÚNICO...}

Renato Almeida de Oliveira / Sandro Soares Rodrigues

segunda, inversamente, a segunda constitui-se como matéria-prima da primeira. Evidentemente, os sistemas filosóficos, os sistemas de educação e as culturas sofrem desgastes com o passar do tempo, porém é neste momento, o de instabilidade, de crise, que os indivíduos têm a matéria-prima para redirecionar e reconstruir a realidade. Contudo, o processo de rebelião, de revolta, por parte dos indivíduos não é espontâneo, ele precisa ser preparado através do processo educativo. Destarte, a educação desponta como peça fundamental e necessária à construção de indivíduos livres e individualidades genuínas.

Para tanto, faz-se necessária a problematização das bases antropológicas, epistemológicas e axiológicas da ação dos indivíduos em um dado momento histórico, criando, a partir de tal reflexão, condições que permitam engendrar intencionalmente a prática educativa voltada à construção crítica do indivíduo.

A educação, consoante Stirner, deve ser construída a partir do princípio da liberdade incondicional do indivíduo. Portanto, a educação informal, ou seja, aquela recebida pelo grupo social na forma da tradição, deve renovar-se, assim como a educação formal, ou seja, aquela recebida institucionalmente, deve ultrapassar os antigos modelos inférteis do humanismo e do realismo. Tais modelos representam a castração das potencialidades e das capacidades inatas dos indivíduos. Segundo Stirner, o desenvolvimento do indivíduo implica no desenvolvimento da sociedade. A tríade educação-indivíduo-sociedade aparece na filosofia stirneriana como indissolúvel, haja vista que "[...] se temos valor, realizaremos coisas de valor: se cada um de nós é perfeito em si, a sociedade e a vida social serão elas também, perfeitas." (STIRNER, 2001, p. $62)$.

Portanto, se a educação é alienante, o indivíduo será alienado e, consequentemente, a sociedade será alienada. Neste caso, o indivíduo não é resultado da contextura social, mas a sociedade é reflexo das possíveis debilidades dos seus membros, individualmente. Da mesma forma, a perfeição social consiste no aperfeiçoamento pessoal, na valorização individual do Eu, do Único.

Na tentativa de problematizar mais detalhadamente os modelos de educação adotados na formação dos homens naquele dado momento, Stirner realiza uma crítica à educação que dotava o indivíduo culturalmente - cultura no sentido estrito, ou seja, pertencente aos cultos, doutos - delegando-lhes poder e autoridade. Neste sentido, a cultura instaurava-se como força, a qual elevava seu portador acima daqueles que não a

\begin{tabular}{|l|l|l|l|l|}
\hline Q Rovista Qialectus & Ano 5 & n. 12 & Janeiro - Julho 2018 & p. 223-240 \\
\hline
\end{tabular}




\section{O PROBLEMA DA EDUCACÃ̃O NA CONSTRUCÃ̃O DO ÚNICO...}

Renato Almeida de Oliveira / Sandro Soares Rodrigues

possuíam. Portanto, “[...] o homem culto desempenhava em seu meio, fosse amplo ou restrito, o papel do forte, do poderoso, daquele que impunha, pois se tratava de uma autoridade." (STIRNER, 2001, p. 63). O acesso à educação era restrito a um pequeno grupo em detrimento de uma grande parcela da população a qual era desprovida da formação intelectual e cultural.

A educação, portanto, criava a segmentação social já que os "homens cultos" dominavam os incultos. Destarte, a educação servia como ferramenta de ascensão ao poder e como meio de sua manutenção, existindo sob a forma exclusivista, particularista. Portanto, “[...] a educação cria a superioridade e faz de vós um senhor; era, então, nesses tempos autoritários um meio de ascender ao poder." (STIRNER, 2001, p. 63). Tal modelo de educação privilegiava a cultura do mundo antigo, representando, para Stirner, “[...] o quanto nossa própria existência parecia desprovida de importância, o quanto estávamos ainda longe de poder criar, por nossa própria originalidade novas formas de beleza, e extrair, de nossa própria razão, a essência da verdade.” (STIRNER, 2001, p. 64).

O humanismo, consoante Stirner, representava a perpetuação do servilismo, do poderio dos senhores sobre os servos. Contudo, as tensões entre o conceito de educação popular e a educação nos moldes humanistas se delinearam mais claramente. A ideologia de poder atrelada à educação confirmava-se ao mesmo tempo em que "[...] se presumia que o povo deveria permanecer ignorante em relação a esses 'senhores instruídos', limitar-se a admirar e a venerar estupidamente esse extraordinário esplendor.” (STIRNER, 2001, p. 65). Portanto, a erudição consistia na aquisição de conteúdos vazios, meramente formais, como o aprendizado de línguas como latim e grego, além de uma educação voltada ao gosto às formas, à elegância.

Stirner passa, no momento seguinte, para uma análise da educação a partir da efervescência social causada pela Revolução Francesa. Segundo tal análise, os princípios revolucionários inspiraram os homens a derrubar o poderio com que fora revestida a educação, além de fomentar a universalização da educação e da cultura. Buscava-se uma educação baseada no reconhecimento dos direitos universais do homem a partir da realidade vivida. Os defensores do realismo defendiam o ensino voltado à técnica, ao útil, ao prático, à realidade, visando a atrair todos os homens à formação escolar, haja vista ser direito de todos o acesso ao saber.

\begin{tabular}{|c|c|c|}
\hline Qenista Dialectus & Ano 5 & n. 12 \\
\hline
\end{tabular}




\title{
O PROBLEMA DA EDUCACÃO NA CONSTRUCÃO DO ÚNICO...
} Renato Almeida de Oliveira / Sandro Soares Rodrigues

Segundo Stirner, a educação passaria do estágio da educação erudita, que representava o poderio de poucos sobre a multidão dos ignorantes, para passar à educação universalista, fonte de um novo tipo de domínio, a saber, a genericidade do indivíduo por meio do ensino e da internalização da ideia de igualdade, liberdade e fraternidade e, consequentemente, da aceitação de sua condição de cidadania e subserviência ao Estado. Segundo Stirner,

\begin{abstract}
A escola, diz-se, deve reconciliar-nos efetivamente com a vida, e preocuparse bastante com ela para que os assuntos que um dia nos interessarão não nos sejam totalmente estranhos, nem impossíveis de compreender. Foi então com mais seriedade que tentaram familiarizar-nos com as situações e com os acontecimentos atuais, e elaboraram programas pedagógicos que deviam aplicar-se a todos, porque eles satisfariam a necessidade, comum a todos os indivíduos, de conhecer seu lugar no mundo e no século. Foi assim que os princípios fundamentais dos direitos do homem tornaram-se vivos e reais nas esferas educativas: a igualdade, pois essa educação concernia a todos, e a liberdade, pois cada um aprendia a conhecer suas próprias necessidades, o que o tornava independente e autônomo. (STIRNER, 2001, p. 67)
\end{abstract}

A crítica de Stirner às correntes educacionais do humanismo e do realismo consiste em afirmar que o primeiro é nostálgico e compreende o passado, enquanto que o segundo, atual, compreende o presente. No entanto, ambas as correntes são apenas ferramentas para dominar questões ligadas à temporalidade e ao fazer, em detrimento do Ser. Em outras palavras, "[...] realismo e humanismo têm uma mesma ideia-mãe, a saber: que a educação tem por objetivo proporcionar ao homem a habilidade." (STIRNER, 2001, p. 69)

O objetivo de Stirner é instaurar um tipo de educação que centre a consciência do indivíduo em torno de si próprio, alcançando, desse modo, a conciliação das dimensões temporal e eterna existente em cada indivíduo. Sua crítica também atacava os conceitos de igualdade e liberdade, pois representavam apenas o modo de negação daquilo que seria o mais importante: a igualdade e a liberdade em relação a si próprio. Segundo Stirner, a igualdade consigo mesmo deve anteceder a igualdade com os demais, e a liberdade deve constituir-se para além do livrar-se da autoridade de outro, mas da afirmação de que nada existe além de si próprio, além do Único.

A crítica stirneriana caminha para evidenciar um fato: o humanismo e o realismo representam a infertilidade das potencialidades do indivíduo, significam apenas modelos que conduzem os indivíduos à alienação, à negação de sua força e ao servilismo voluntário. Tanto o humanismo quanto o realismo produziram, segundo

\begin{tabular}{|c|c|c|}
\hline Q Rovista Dialectus & Ano 5 & n. 12 \\
\hline
\end{tabular}



Renato Almeida de Oliveira / Sandro Soares Rodrigues

Stirner, o dandismo e o industrialismo ${ }^{8}$, ou, em outras palavras, a atrofia do homem ou pelo viés do apego à preocupação com as formas e com os modos refinados, ou à extrema atenção ao tecnicismo. Destarte, percebemos que a educação, transmitida no âmbito escolar serve como meio de manutenção do poder estatal sobre os indivíduos, ou no caso, sobre o cidadão.

Contudo, a superação do Estado (instituição) ou do estado de coisas vigente, depende da dissolução daquilo que representa a deformação das consciências, ou seja, a cultura e a educação promovidas em prol da dominação dos indivíduos pelo Estado, haja vista que "Nisto consiste o tipo de cultura e formação que o Estado pode me dar: educame para eu ser uma 'ferramenta útil', um 'membro útil da sociedade'”. (STIRNER, 2009, p. 288). A essência do Eu, nesta perspectiva fora invertida, colocada fora do indivíduo, num plano meramente abstrato, formal. A luta do egoísta é chegar, liberto das imposições culturais, ao seu Eu legítimo, verdadeiro.

Não importa o tipo de governo, o Estado sempre buscará aniquilar o indivíduo, o qual vive ao mesmo tempo que decreta a morte daquele.

[...] o Estado tem sempre uma única finalidade: limitar o indivíduo, refreá-lo, subordiná-lo, fazer dele súdito de uma ideia geral; só dura enquanto o indivíduo não for tudo em tudo, e é apenas a mais marcada expressão da limitação do meu eu, da minha limitação e da minha escravidão. (STIRNER, 2009, p. 291)

Stirner aponta que a educação voltada à manutenção do poder do Estado inicia-se desde a primeira fase da vida dos cidadãos, ou seja, desde criança existe uma conformação dos indivíduos a aceitarem a condição de submetidos às leis, de receptores

8 Adotaremos a interpretação realizada por J. Barrué: “O dandismo surgiu na Inglaterra por volta de 1815. O dândi, a origem da palavra parece desconhecida, pertence à juventude dourada, isso pode ser observável por sua suprema elegância, os contornos de suas vestes, a cor cuidadosamente estudada de seu paletó ou de seu redingote. Aspira tornar-se, como Geoge Brummel, o rei da moda, e é, em 1830, o modelo no qual vão se inspirar em Paris e nas grandes capitais, os filhos de família e os fashions. Fala de cavalos e mulheres, é desenvolto, impertinente, irônico, de bom grado ímpio, mas sempre conservador. [...] industrialismo, é bem evidente que Stirner não ataca o proprietário de fábrica ou de manufatura. Creio que se deve ver no emprego dessas palavras uma alusão direta à escola saintsimoniana. [...] as teorias de Saint-Simon tendiam a uma reabilitação da matéria, previam o imenso futuro da técnica transformando a sociedade e resolvendo a questão social, e opunham-se irredutivelmente ao idealismo da filosofia alemã. [...] para Saint-Simon, a sociedade tem por fundamento a indústria. Ele vê no homem não o consumidor, mas o produtor (ou ainda o empreendedor, o industrial). [...]compreende todos aqueles que desempenham um papel efetivo na produção: operários, engenheiros, chefes de empresas, aos quais ele acrescenta os banqueiros e os trabalhadores intelectuais, os homens de ciência e os artistas. A produção de coisas uteis é o único objetivo razoável e positivo que as sociedades políticas possam propor a elas mesmas." (Cf. STIRNER, 2001, p. 44-47).

\begin{tabular}{|l|l|l|l|l|}
\hline Qevista Oialectus & Ano 5 & n. 12 & Janeiro - Julho 2018 & p. 223-240 \\
\hline
\end{tabular}




\section{O PROBLEMA DA EDUCACÃO NA CONSTRUCÃO DO ÚNICO... Renato Almeida de Oliveira / Sandro Soares Rodrigues}

de direitos, por meio de um processo contínuo de adestramento, o qual se constitui como inibidor da força, do egoísmo e do poder individual. Por esta razão, Stirner identifica a escola como a primeira forma de impressão do servilismo nos homens. Conforme Kassik, a escola " [...] ensina a dominar determinadas coisas através de dados conhecimentos e, sobretudo, a dominar a nossa natureza, isto é, a nos controlar, a nos disciplinar em sociedade, e não em nos tornar homens livres e autênticos.” (KASSICK, 2005, p. 30-31).

As instituições que formam o corpo do Estado são por natureza coibidoras das liberdades, aniquiladoras das individualidades. Neste sentido, a escola representa o lugar eminente da sujeição, de subjugação do indivíduo. Do ponto de vista stirneriano, a função primordial da escola é diluir a vontade da criança, tendo como objetivo dominar o futuro adulto, desprovido de força e de vontade, transformando-o em um bom cidadão cumpridor dos deveres e adorador do poder estatal. Nas palavras de Stirner:

\footnotetext{
[...] um Estado existe sem que eu tenha de fazer nada por isso: eu nasço nele, cresço nele, tenho meus deveres para com ele e tenho de lhe "prestar homenagem". Por sua vez, o Estado recebe-me em sua "graça" e vivo dela. Assim, a existência autônoma do Estado fundamenta minha dependência; sua "naturalidade", seu organismo, exigem que minha natureza não cresça livremente, mas se lhe ajuste. Para que ele possa se desenvolver de forma natural, aplica-me a mim a tesoura da "cultura"; dá-me uma instrução e uma educação que lhe servem a ele, mas não a mim, e ensina-me, por exemplo, a respeitar as leis, a não agir contra a propriedade do Estado (isto é, propriedade privada), a venerar uma autoridade, divina e terrena etc., em suma, ensina-me a ser irrepreensível, exigindo com isso que eu "sacrifique" minha singularidade própria a algo de "sagrado" (e muitas coisas podem ser sagradas, por exemplo, a propriedade, a vida dos outros etc.). (STIRNER, 2009, p. 287-288)
}

A sociedade, consoante Stirner, parte do pressuposto de que existe uma sequencialidade entre escolarização, cultura e liberdade. Portanto, para vivenciar a liberdade, o indivíduo deverá alcançar níveis elevados de escolarização e de cultura. $\mathrm{O}$ posicionamento de Stirner afirma o contrário: quanto mais culto o sujeito, mais domesticado, adestrado, pois a cultura, para ser reconhecida dentro do Estado, está submetida à escolarização e, logo, o nível de escolarização corresponde ao nível de condicionamento e regramento social a qual tal sujeito fora exposto. A cultura, no sentido de valores estritamente formais, atrelados à ideologia dominante, surge como inimiga da liberdade e, consequentemente, do Único.

A educação estatal abafa os impulsos de vida dos indivíduos, tornando-os vazios de sentido, impotentes, isolados. Stirner é acusado por seus opositores de afastar os indivíduos pelo egoísmo, contudo, segundo nosso autor, aquele que isola os indivíduos

\begin{tabular}{|c|c|c|}
\hline Q Rovista Dialectus & Ano 5 & n. 12 \\
\hline
\end{tabular}




\section{O PROBLEMA DA EDUCAC̄̃̃O NA CONSTRUCÃO DO ÚNICO... Renato Almeida de Oliveira / Sandro Soares Rodrigues}

uns dos outros é o Estado, através da normatização imposta e assumida por estes. A capacidade de insurgência dos indivíduos é castrada desde a primeira infância pela aplicação de diversos meios de coerção e continua até a vida adulta. A vitalidade egoística é estigmatizada, criminalizada e banida.

Ao promover a construção do Único, Stirner realiza uma denúncia contra os mecanismos de controle utilizados pelo Estado. $\mathrm{O}$ enfraquecimento da força individual associada ao isolamento estimulado pela educação e pela escola representam a força suprema de dominação sobre as individualidades, pois se trata da intervenção sobre a formação intelectual, física, psicológica e social de cada sujeito. A escola deforma o indivíduo, condiciona-o a negar sua vontade, retira-lhe aquilo que lhe é mais caro: sua singularidade, sua unicidade. Portanto, “[...] a escola não forma homens tão profundamente verdadeiros; se, contudo, há alguns deles, é certamente malgrado a escola.” (STIRNER, 2001, p 75-76)

Stirner remete à educação condicionada aos interesses escusos do Estado a causa primeira da alienação dos indivíduos. Consoante KASSICK (2001), a educação estatal, a partir da normatização social e política, vilipendia a soberania da individualidade, apartando o homem de si mesmo, incutindo seus atributos à individualidade, sujeitando-a, diluindo-a em favor de um Eu social vazio, abstrato. Contudo, não basta identificar o problema, mas apontar possíveis soluções. Se existe o plano de construção de um novo exemplar de indivíduo, e se os modelos vigentes de educação não serão capazes de fazê-lo, qual a solução apontada por Stirner a tal problema? Seguiremos nossa investigação na tentativa de apresentar a elucidação stirneriana ao problema prático de criação do Único.

\section{A educação para a unicidade}

O ponto de partida para toda a filosofia do Eu radical e absoluto, como vimos, deve partir da educação. Stirner proclama a necessidade de uma reviravolta, de uma revolta personalista ${ }^{9}$ na educação, pautada na postura antiautoritária, na valorização da criança e de sua condição infantil, e no fomento e fortalecimento da personalidade, identidade e individualidade únicas. A proposta de Stirner almeja alcançar tanto os

9 A utilização do termo personalismo dá-se de forma distinta da concepção psicológica de personalismo e personalidade. Consiste em designar à personalidade como formação de um sujeito, de um indivíduo portador de vontade, ou seja, o egoísta, o Único. (Cf. KASSICK, 2001, p. 23).

\begin{tabular}{|l|l|l|l|l|}
\hline Q Rovista Dialectus & Ano 5 & n. 12 & Janeiro - Julho 2018 & p. 223-240 \\
\hline
\end{tabular}




\section{O PROBLEMA DA EDUCACÃ̃O NA CONSTRUCÃ̃O DO ÚNICO... Renato AImeida de Oliveira / Sandro Soares Rodrigues}

indivíduos que estão iniciando seu processo de formação e aprendizagem, como aqueles que já sofreram a influência da educação humanista ou realista, dando-lhes a oportunidade de resgatar sua unicidade outrora roubada. Portanto, o modelo de educação imposto pelo Estado deve ser negado, superado.

Consoante Stirner, o indivíduo deve lutar pelo direito inalienável de sua personalidade, derrubando todo tipo de dominação ou de poder que se coloque como empecilho. A educação personalista, nos moldes stirnerianos, tornará o indivíduo poderoso contra as vontades alheias, sejam elas institucionais ou pertencentes a outros indivíduos. Por isso, a força e o poder individual nortearão a concepção de educação individualista proposta por Stirner.

Notoriamente, a proposta stirneriana de educação, ao contrário dos modelos tradicionais, não nutre nenhuma expectativa em relação ao cultivo de modelos ou arquétipos a serem alcançados. Em outros termos, enquanto a educação tradicionalista busca alcançar um determinado tipo de personalidade ou de comportamento, a educação para a unicidade preconiza o desenvolvimento da personalidade individual, do egoísta. Destarte, Stirner defende que cada indivíduo tenha a liberdade de desenvolver suas características peculiares, próprias, sendo respeitada e defendida sua personalidade e, consequentemente, sua individualidade.

Stirner propõe uma reflexão e uma revolução na educação, apontando uma questão central: “[...] o que fizeram e o que se propõem a fazer de nós; [...] cultivam, em consciência, nossa predisposição à criação ou nos tratam apenas como criaturas unicamente suscetíveis de adestramento?”. (STIRNER, 2001, p. 61-62)

Conforme percebemos, o personalismo proposto por Stirner implicará em mudanças significativas no processo de escolarização, pois afetará estruturalmente as relações de ensino-aprendizagem, assim como as relações de poder inerentes ao âmbito da escola. A discussão em torno da educação configura-se como a mais proeminente, tendo em vista ser esta a experiência definidora das personalidades e, consequentemente, da configuração social e política. Afirma Stirner:

O que importa, portanto, de início, é o que fizeram de nós na idade em que ainda somos maleáveis; o problema escolar é um problema vital. Isso salta aos olhos hoje; luta-se nesse terreno há muito tempo com um ardor e uma franqueza que ultrapassam de longe aquelas exibidas no campo da política, pois lá não se combate as obstruções do poder arbitrário. (STIRNER, 2001, p. 62). 


\section{O PROBLEMA DA EDUCACÃ̃O NA CONSTRUCÃ̃O DO ÚNICO...} Renato Almeida de Oliveira / Sandro Soares Rodrigues

A educação tornou-se, ao longo do tempo, a ferramenta pela qual a sociedade, por meio de suas instituições, modela os indivíduos de acordo com seus objetivos, extirpando as vontades individuais, a capacidade de insurgência e de crítica dos indivíduos, impedindo-os de perseguirem outras possibilidades de relações sociais.

É mister perguntarmo-nos a quem caberia a responsabilidade de ocupar o posto de educador, haja vista a limitação dos realistas e dos humanistas. De fato, os opositores de Stirner, humanistas e realistas, indagaram-no se o encargo de ensinar deveria ser dos filósofos, ao que Stirner respondeu: “[...] desejaríamos, por acaso, colocar a pedagogia nas mãos dos filósofos? De modo algum! Eles se comportariam com inabilidade. Não se confiará a pedagogia senão àqueles que são mais que filósofos, portanto, infinitamente mais que humanistas e realistas." (STIRNER, 2001, p. 72).

Ao realizar a crítica à educação nos moldes humanista e realista, Stirner destaca que, em um e outro caso, existe a sacralização, a dogmatização, o endeusamento do conhecimento, elevando-o ao posto de verdade absoluta. No humanismo, a verdade é revelada; no realismo, ela deve ser descoberta. Então, o conhecimento torna-se anterior e independente ao indivíduo. Portanto,

\footnotetext{
Nem humanistas nem realistas, mas personalistas. Não ao vazio da educação elegante. Não ao praticismo do realismo, mas sim a utilização do conhecimento para a afirmação da personalidade, das individualidades e, sobretudo, da vontade que possibilita este desenvolvimento. O saber não deve tornar-se o novo senhor que escraviza as vontades. (KASSICK, 2005, p. 27).
}

O saber, segundo Stirner, deve ser transmutado em vontade geradora de vida, de criatividade e de autonomia da personalidade. $\mathrm{O}$ conhecimento e o saber, enquanto representações de modelos e parâmetros predeterminados ou estabelecidos como imutáveis, gera a debilidade e a estagnação dos indivíduos. Neste caso, o saber deve passar por um processo de dessacralização, deixando de ser verdade absoluta para ser verdade questionável. O saber como verdade indubitável existe como reprodução, não podendo ser reinventado, ressignificado ou renovado. Logo, o Único stirneriano não adota verdades eternas, pois as verdades são criadas e recriadas a partir de seu caráter transitório e utilitário, para o bem do indivíduo.

O conhecimento, segundo Stirner, tem a utilidade de clarificar o indivíduo em relação à sua capacidade de querer e de realizar aquilo que deseja. A liberdade consiste na capacidade do indivíduo de ser possuidor; portanto, as propostas e ideologias do liberalismo são limitadas, haja vista que “[...] as liberdades de pensamento, de crença e de

\begin{tabular}{|l|l|l|l|l|}
\hline Rovista Dialectus & Ano 5 & n. 12 & Janeiro - Julho 2018 & p. 223-240 \\
\hline
\end{tabular}




\section{O PROBLEMA DA EDUCAC̄̃̃O NA CONSTRUCÃO DO ÚNICO... Renato Almeida de Oliveira / Sandro Soares Rodrigues}

consciência, essas flores maravilhosas que são obra de três séculos, se fecharão no seio da terra para nutrir com suas mais preciosas seivas uma nova liberdade, a liberdade de querer.” (STIRNER, 2001, p. 72-73). A concepção de educação transmuta-se da mera recepção e acúmulo de informação para a capacidade de converter tais conhecimentos em vontade. Por isso, a não submissão à soberania do conhecimento, seja ele científico, moral ou religioso, confere autonomia ao indivíduo frente ao outro, possibilitando a apropriação de si, da gestação de sua vontade própria, tornando-se o determinador de sua vontade e de sua ação, tornando-se Único.

Portanto, a educação, assume como finalidade a unicidade do indivíduo, distinguindo-se da proposta hegeliana de uma educação para a cidadania ou da Educação Kantiana para a Moralidade. Destarte, a finalidade da educação consiste em possibilitar ao indivíduo que ele possa, por suas capacidades, transformar o saber em vontade, em sua vontade. Em outros termos,

[...] o saber autêntico encontra seu acabamento cessando de ser saber e tornando a ser um simples desejo instintivo do homem: a Vontade. [...] Eis aí o ponto final e, ao mesmo tempo, a perenidade, a eternidade do saber. Repentinamente, tornado a ser simples e direto, o Saber, sob uma nova forma, manifesta-se e recria-se em vontade em todas as nossas ações. (STIRNER, 2001, p. 74).

As transformações necessárias à execução do novo modelo de educação formadora e formativa do Único deve passar por algumas etapas, partindo da conversão do sentido de poder delegado à educação durante séculos, passando pela mudança da concepção de autoridade encarnada pelos professores ou mestres-escola, até culminar na modificação da finalidade educativa, passando da formação de homens do saber e do fazer, para a formação de indivíduos dotados da capacidade do querer, da vontade e da força.

É mister ressaltar que o indivíduo, para desenvolver a Vontade, o egoísmo e a autonomia, necessita de um espaço escolar completamente inverso daquele existente: um espaço no qual a subserviência abra espaço para a criticidade; no qual a instrumentalização dê lugar à criatividade e inventividade; no qual o professor deixe de ser instrutor e mestre para se tornar um colaborador; e, principalmente, no qual o saber alienante abra espaço para um tipo de saber transfigurado em vontade e que o homem educado, erudito, culto, técnico desapareça diante do indivíduo livre.

Como podemos constatar, a liberdade stirneriana consiste em apropriar-se das coisas por meio da força individual. Portanto, a educação deve preparar os indivíduos

\begin{tabular}{|l|l|l|l|l|}
\hline Q Rovista Qialectus & Ano 5 & n. 12 & Janeiro - Julho 2018 & p. 223-240 \\
\hline
\end{tabular}




\section{O PROBLEMA DA EDUCACÃ̃O NA CONSTRUCÃ̃O DO ÚNICO...}

Renato AImeida de Oliveira / Sandro Soares Rodrigues

para, a partir do desenvolvimento de suas potencialidades, alcançarem a autonomia, fruto da autodeterminação da vontade, gerando um novo modelo de auto-organização social.

Stirner defende a educação personalista por acreditar ser este o modelo capaz de promover o autoconhecimento, a valorização da individualidade, a afirmação do homem singular, senhor de si e do mundo. O autorreconhecimento é a condição necessária para que o indivíduo externe o poder de sua vontade. Tal poder só pode emergir se o espaço educativo permitir o total desenvolvimento das forças individuais, ou seja, se permitir que as características próprias de cada um possam florescer. Segundo Stirner, a escola tradicional instrui os indivíduos adaptando-os às conveniências sociais e submetendo-os a uma permanente negação de si, fazendo-os progressivamente submissos.

O papel da educação deve ser o de favorecer a transformação do saber, enquanto propriedade e poder, em capacidade de se tornar autoconsciência do espírito, vontade. A educação deve ser pautada no caráter pessoal, individual, ao contrário da uniformização promovida pelo humanismo e pelo realismo. Esta não deve ser posse, mas incorporada ao indivíduo como parte integrante de sua existência.

Nesta perspectiva, a insubordinação e a revolta da criança devem ser incentivadas, pois é no momento de insurreição diante de outro (instituição ou pessoa) que o indivíduo se afirma como Único e ocupa o seu lugar no mundo. A escola, na perspectiva de Stirner, deve facilitar a formação do indivíduo para a independência, a contestação, o egoísmo e a utilidade. Destarte, o papel da escola não será de instruir ou civilizar, mas favorecer a expressão da criatividade e da personalidade irrepetível e fecunda presente em cada individualidade. Desse modo, o conhecimento deve ser assimilado de forma reflexiva e crítica, pois “[...] o homem só é livre se tiver dominado o saber adquirido e reintegrado o que dele extraiu por suas indagações na unidade de seu Eu." (STIRNER, 2001, p. 75).

\section{À guisa de conclusão}

Percebemos a audácia de Stirner ao propor um modelo de educação libertária em um contexto de sociedade voltada à disciplina escolar rigorosa, como era a escola prussiana em meados do século XIX.

A luta de Stirner dar-se-á contra o autoritarismo presente no âmbito escolar, pois, segundo ele, este modelo ensinado e aprendido será posteriormente reproduzido na

\begin{tabular}{|l|l|l|l|l|}
\hline Q Rovista Dialectus & Ano 5 & n. 12 & Janeiro - Julho 2018 & p. 223-240 \\
\hline
\end{tabular}




\title{
O PROBLEMA DA EDUCACÃO NA CONSTRUCÃO DO ÚNICO...
} Renato Almeida de Oliveira / Sandro Soares Rodrigues

esfera da vida social, através de um ciclo infinito de dominação-subordinação. A escola tradicional uniformiza os indivíduos, adestrando-os à vida coletiva, em detrimento de sua individualidade. Evidenciando-se então que

\begin{abstract}
Em pedagogia, como em outros campos, a liberdade não pode expressar-se, nossa faculdade de oposição não pode exprimir-se; exigem apenas submissão. O único objetivo é adestrar à forma à matéria: do estábulo dos humanistas não saem senão letrados, do estábulo dos realistas, só cidadãos utilizáveis e, em ambos os casos, nada além de indivíduos submissos. (STIRNER, 2001, p. 77)
\end{abstract}

Stirner denuncia que aqueles que não se submetem às regras ou aos modelos estabelecidos são renegados através de humilhações, repetições de série ou expulsão do sistema educacional. Ao contrário, aqueles que se permitem adestrar recebem méritos, honras e reconhecimento. Na perspectiva stirneriana, quanto mais mérito alguém galgar, mais dominado e débil estará. Neste caso, o Único, dentro do sistema humanista/realista, será degredado e excluído.

A cultura da meritocracia e da militarização da educação foi veementemente criticada por Stirner. O conhecimento tornou-se moeda de troca e de status social e, segundo ele, é a partir da sujeição à escola que tem início toda a cadeia de posteriores subordinações, como igreja, sindicato, fábrica etc. A alienação, segundo Stirner, não é proveniente da divisão social do trabalho, mas da negação e da anulação da vontade do indivíduo. Segundo Tomassi (1988), desde a tenra infância o indivíduo estuda com a finalidade de adquirir informação, não de criar. A educação e a cultura servem como fontes de alienação ao invés de serem fontes de tomada de consciência e, portanto, um ensinamento à autonegação e à humilhação. Em tom de denúncia, Stirner brada sua revolta ao afirmar que

\footnotetext{
A miséria de nossa educação até os nossos dias reside em grande parte no fato de que o saber não se sublimou para tornar-se Vontade, realização de si, prática pura. Os realistas sentiram essa necessidade e preencheram-na, mediocremente por sinal, formando "homens práticos" sem ideias e sem liberdade. A maioria dos futuros mestres é o exemplo vivo dessa triste orientação. Cortaram-lhes magnificamente as asas: agora é sua vez de cortar as dos outros! Foram adestrados, é sua vez de adestrar! Todavia, a educação deve ser pessoal, mestre do Saber e guardar constantemente no espírito esse caráter essencial do Saber: não ser em nenhum caso objeto de posse, mas ser o próprio Eu. (STIRNER, 2001, p. 81).
}

O grande problema apontado por Stirner remete-nos à questão de que a educação formal se pauta sobre um saber desprovido de Vontade e, por isso, vazio. Para

\begin{tabular}{|l|l|l|l|l|}
\hline Rovista Dialectus & Ano 5 & n. 12 & Janeiro - Julho 2018 & p. 223-240 \\
\hline
\end{tabular}




\section{O PROBLEMA DA EDUCAC̄̃̃O NA CONSTRUCÃO DO ÚNICO... Renato Almeida de Oliveira / Sandro Soares Rodrigues}

ele, “[...] o Saber deve morrer para ressuscitar como Vontade e recriar-se a cada dia como livre personalidade." (STIRNER, 2001, p. 85). O que Stirner almeja não é, como afirmam alguns, que haja a concordância entre a escola e a vida, mas que a escola seja a vida, pois, somente a partir dessa reviravolta de perspectiva, o indivíduo terá a possibilidade de autoconstrução e autorrevelação. Dessa forma, a educação deve cultivar a liberdade, pois nisto consiste a igualdade verdadeira e a "verdadeira vida." (STIRNER, 2001, p. 83)

Logo, o Único, para poder existir, terá que se livrar das amarras da educação formal, da cultura e da moral. Compete ao homem o aprendizado ao pensamento crítico, desembaraçado dos temores e da tradição; ou seja, o indivíduo é o primeiro responsável por sua autoformação, ou autoeducação. A moral, em seus diversos níveis de aparição, representa a limitação do desenvolvimento do indivíduo, pois incute o medo, a culpa e o falso espírito de responsabilidade e de dever. A educação não deve incutir hábitos morais nos indivíduos, assim como não deve adestrá-lo a negar sua individualidade, sua vontade, em detrimento de qualquer causa que seja, pois só existe uma causa para o Único: ele próprio. Stirner propõe uma postura amoral como condição de existência do indivíduo livre, pois a moral não permite a manifestação da pluralidade e da multiplicidade das personalidades. A educação formativa do Único preza pela unicidade, e não pela diferença entre os indivíduos; ou seja, não devem existir parâmetros comparativos entre as características individuais, e sim o espaço no qual estas personalidades fluem autonomamente. O Único não é formado para a igualdade, pois esta representa a homogeneização e uniformização, ao passo que o indivíduo deve ser preparado para a multiplicidade.

O Estado teme o Único, pois este não se submete à normatização por meio da moral social e do legalismo, não se preocupando em ser encaixado nos moldes da justiça, da legalidade ou da moralidade. Em outras palavras,

[...] o fundamento do egoísta se alicerça na afirmação de que o homem é o que o seu poder permite sem constrangimentos, seja pela moral ou por qualquer outro elemento. Portanto, a liberdade é o estado que permite ao homem o exercício pleno de seu poder de ser. (KASSICK, 2005, p. 58).

A educação deverá fomentar a liberdade do pensamento, da consciência do indivíduo, porque nem a liberdade política, nem a liberdade religiosa, e muito menos a liberdade humana poderão garantir a verdadeira autonomia. Somente um indivíduo que

\begin{tabular}{|l|l|l|l|l|}
\hline Q Rovista Qialectus & Ano 5 & n. 12 & Janeiro - Julho 2018 & p. 223-240 \\
\hline
\end{tabular}


conquistou a autoconsciência, pode autodeterminar-se. É a autodeterminação que permite ao sujeito criar a sua subjetividade por meio do empossamento de si e daquilo que conquistou exteriormente, configurando-se como individualidade autônoma.

\section{REFERENCIAS}

STIRNER, Max. O falso princípio da nossa educação. Tradução de Plínio Augusto Coêlho. São Paulo: Imaginário, 2001.

Fontes, 2009.

O único e a sua propriedade. Tradução de João Barrento. São Paulo: Martins

ARANHA, Maria Lúcia de Arruda. Filosofia da educação. 3. ed. ver. e ampl. São Paulo: Moderna, 2006.

BARRUÉ, Jean. Lendo o Único. In: COÊLHO, Plínio Augusto (Org.). Max Stirner e o anarquismo individualista. Tradução de Plínio Augusto Coêlho. São Paulo: Imaginário, 2003.

DÍAZ, Carlos. Uma filosofia radical do Eu. Tradução de Piero Anragano e Jorge E. Silva. São Paulo: Imaginário: Expressão e Arte, 2002.

FERRER, Christian. Max Stirner: autor de um Único livro. In: STIRNER, Max. O falso princípio da nossa educação. Tradução de Plínio Augusto Coêlho. São Paulo: Imaginário, 2001.

KASSICK, Clovis N. A filosofia do eu. Rio de janeiro: Achiamé, 2005.

LEVY, Albert. Stirner e Nietzsche. In: COÊLHO, Plínio Augusto (Org.). Stirner e Nietzsche. Tradução de Plínio Augusto Coêlho. São Paulo: Expressão e Arte: Imaginário, 2012.

SCHAFF, Adam. O marxismo e o indivíduo. Rio de Janeiro: Civilização Brasileira, 1967.

SOUZA, José Crisóstomo. A questão da individualidade: a crítica do humano e do social na polêmica Stirner-Marx. Campinas: Editora Unicamp, 1993.

TOMASSI, Tina. Breviario del pensamiento educativo libertário. Colombia: Outra Vuelta de Tuerca, 1988.

VAZ, Henrique Cláudio de Lima. Escritos de filosofia III: Cultura e Filosofia. São Paulo: Edições Loyola, 1997.

\begin{tabular}{|l|l|l|l|l|}
\hline Q Ponista Dialectus & Ano 5 & n. 12 & Janeiro - Julho 2018 & p. 223-240 \\
\hline
\end{tabular}

